Sidransky, H. \& Baba, T. (1960). F. Nutr. 7o, 463.

Sidransky, H. \& Farber, E. (1958). Arch. Path. 66, 135.

Smith, G. H. \& Lewis, D. (1964). Proc. Nutr. Soc. 23, xxviii.

Spolter, P. D. \& Harper, A. E. (1961). Amer. Y. Physiol. 200, 513.

Tarver, H. ( $\mathrm{Ig63}_{3}$ ). In The Liver. Vol. 1, p. 450. [C. Rouiller, editor]. New York: Academic Press Inc.

Waisman, H. A. \& Harlow, IH. F. (1965). Science, 147, 685.

\title{
The balancing of amino acid mixtures and proteins
}

\section{By A. E. Bender, Department of Nutrition, Queen Elizabeth College, London, W8}

In discussing imbalance or unbalance it is desirable to know the composition of the ideal mixture of amino acids which might be described as constituting perfect balance. The work reported here was directed towards correlating nutritive value (biologically determined) of proteins and amino acid mixtures of known composition with their amino acid make-up. The results may be applied to answer whether deviations from the ideal composition create an imbalance, and whether the relation between chemical score and biological value would be upset by such an imbalance.

The results reported in this paper have not been presented before except at a special meeting of the Committee on Protein Malnutrition (Bender, 196r).

The ideal mixture, i.e. perfect balance, is defined as that which has a biological value of 100 when given to the rat at $\mathrm{I} \cdot 6 \%$ nitrogen level.

\section{Methods}

Net protein utilization was measured by the carcass analysis method (Miller \& Bender, 1955); digestibility was measured in the same experiment and biological value (Bv) was calculated from net protein utilization (NPU) divided by digestibility (D).

In the amino acid diets the L-forms of histidine, lysine and leucine were used, and the DL-forms of the other amino acids at double the level of the L-isomer required, except for methionine of which the D-form is fully utilized (Berg, I959). Non-essential amino acids were supplied as a mixture of equal parts of glycine, arginine, alanine and glutamate to avoid an excess of any one amino acid. The unusable D-forms of the essential amino acids were included with the non-essential nitrogen for the purposes of calculation.

\section{Evaluation of egg protein}

In calculating chemical scores, Block \& Mitchell (1946-7) and subsequent workers used egg protein as the standard, regarding this as the best available approach to the perfect protein. Apart from the question of the accuracy of the analysis (Bender, 1954) errors could arise if egg protein contains one or more essential amino acids in quantities greater than required by the rat. Such a surplus would not be revealed by a biological assay but would cause an error in estimating chemical score. If the essential amino acid in question were present in egg in amount greater than $100 \%$ of the rat's needs then the chemical score would be undervalued. 
The $\mathbf{B v}$ of defatted, dried egg was determined five times with a mean result of 97 (individual results $97,99,88,98$, 103). There was thus no evidence of a deficiency of lysine, as was suggested by Mitchell (1959) as a result of growth experiments.

The egg protein was diluted by the addition of $15 \%$ of its weight of a mixture of equal parts of the non-essential amino acids, alanine, glycine, arginine and glutamate. The BV was 96 (individual values 92 and 99), indicating that egg protein contains a surplus of at least $10 \%$ of all the essential amino acids.

In a second test the egg protein was diluted by adding $30 \%$ of the non-essential amino acid mixture; the $\mathbf{B V}$ fell to 82 (individual values 78 and 86 ). Thus the surplus of all the essential amino acids was less than $20 \%$.

\section{Amino acid mixtures}

Of the published analyses of egg protein, that determined in the Rutgers Cooperative Test (Rutgers University: Bureau of Biological Research, 1950) was selected as it was the result of eleven collaborative determinations. This analysis (Table I) gives

\section{Table 1. Amino acid composition of egg protein and target mixture}

$\begin{array}{lccc}\text { Rutgers University: Bureau } & \begin{array}{c}\text { Target mixture } \\ \text { (lowest level of each } \\ \text { amino which would } \\ \text { still give BV 100) }\end{array} & \begin{array}{c}\text { Target values expressed } \\ \text { as percentage of amino } \\ \text { acid levels used by } \\ \text { Block \& Mitchell (1946-7) }\end{array} \\ \begin{array}{l}\text { Amino acid } \\ \text { 'best selected values' }\end{array} & \begin{array}{c}\text { I } \\ \text { Histidine }\end{array} & 2 \cdot 8 & 86 \\ \text { Lysine } & 6 \cdot 1 & 5 \cdot 2 & 72 \\ \text { Tryptophan } & 1 \cdot 1 & 1 \cdot 0 & 67 \\ \text { Phenylalanine } & 5 \cdot 6 & 4 \cdot 9 & \\ \text { Methionine } & 3 \cdot 2 & 2 \cdot 7 & 73 \\ \text { Cystine } & 2 \cdot 3 & 2 \cdot 0 & 84 \\ \text { Threonine } & 4 \cdot 9 & 4 \cdot 1 & 85 \\ \text { Leucine } & 9 \cdot 0 & 7 \cdot 8 & 54 \\ \text { Isoleucine } & 6 \cdot 2 & 4 \cdot 3 & 69 \\ \text { Valine } & 7 \cdot 0 & 5 \cdot 0 & \end{array}$

lower values for lysine and cystine plus methionine than those used by Block \& Mitchell (1946-7) for calculating chemical score.

An amino acid mixture was prepared on the Rutgers pattern with double quantities of DL-forms where necessary and a mixture of the four amino acids listed above as a source of non-essential amino acids. The BV of the mixture was 89 (individual values $9 \mathrm{I}$ and 87 ). The mixture was diluted by adding $15 \%$ of the non-essential amino acid mixture; the BV was then 96 (individual values 92 and 99). The value of 96 was accepted as evidence that the original mixture contained a surplus of the essential amino acids and the rather low value of 89 before dilution was attributed to experimental error.

To determine the extent of the surplus, a series of amino acid mixtures was prepared patterned after egg protein except that each amino acid in turn was halved in quantity. If the original mixture represented the perfect protein or ideal mixture then each of the 'half mixtures' should have had a BV of 50. Any result greater than 24 (2) 5 
50 indicated that the amino acid halved in that mixture must have been present in the original mixture at more than $100 \%$ of the rat's requirements.

The results shown in Table 2 suggest that lysine was present at the required level

\section{Table 2. Biological value for rats of 'half-amino acid mixtures' *}

Amino acid halved
in quantity
Lysine
Histidine
Tryptophan
Phenylalanine
Cystine + methionine
Threonine
Leucine
Isoleucine
Leucine + isoleucine
Valine

Replicates
49,54
$45,65,67$
$92,82,96,77$
$75,65,82,75$
54,58
63,61
63,58
37,29
62,49
71,71

Percentage of rat's

requirements in mixture simulating egg

*A mixture of amino acids simulating egg protein according to the analysis of the Rutgers University: Bureau of Biological Research (1950) with each amino acid in turn halved in quantity.

in the original mixture, as the BV of its 'half mixtures' was close to 50 , and their calculated surplus in the original mixture is shown in Table 2.

The 'half isoleucine mixture' had BV 33 ; when leucine as well as isoleucine was halved, the $\mathrm{BV}$ rose to 56 . This result would appear to have been due to an imbalance between these two amino acids and they have, therefore, been considered together.

\section{Target mixture}

The findings with the 'half amino acid mixtures' showing lysine present in the original mixture patterned on egg at $100 \%$ of the rat's requirements are in conflict with the results of the egg dilution experiment, which shows all the essential amino acids to be present in surplus. 'This conflict might have been due to experimental error or to the unusual effects observed with lysine, such as the NPU of approximately 40 found with mixtures lacking lysine (see p. 193). The remaining nine amino acids were all present in excess according to both methods.

In the first trial to prepare the ideal mixture to be used as the target mixture (i.e. the lowest level of each amino acid which would still give $\mathrm{BV}$ 100), in comparing chemical scores, the lowest value for each amino acid found by either method was taken. This mixture did not give a $\mathrm{BV}$ approaching 100 until the levels of tryptophan and phenylalanine were increased to the higher level deduced from the egg dilution experiment. The final target mixture is listed in Table $\mathrm{I}$ and had a BV of 96 (individual values 92 and 99). The net protein ratio (NPR) (Bender \& Doell, I957) was 5.52 ; the protein retention efficiency (PRE) (Bender \& Doell, I957) was 89; and the protein efficiency ratio (PER) was $2 \cdot 38$. For egg the BV was 99 , NPR $6 \cdot$ I, PRE 98 and PER 4.0. The low PER of the amino acid mixture compared with that of egg was probably due to the lower food intake with the amino acid mixtures (Bender, 1956), namely $9.5 \mathrm{~g} / 100 \mathrm{~g}$ body-weight daily, compared with $13 \mathrm{~g}$ of the egg diet. 
Correlation of chemical score with $\mathrm{BV}$

The target amino acid mixture with BV approximately Ioo establishes the maximum point on the curve relating chemical score with BV.

To determine the mid-point, a series of mixtures was prepared in which one amino acid was made limiting at chemical scores of from 50 to 75 and the BVs were determined. The Bvs were always numerically equal to the chemical scores (Table 3 ), i.e. there was no evidence of imbalance.

Table 3. Comparison of chemical score with biological value for rats of mixtures of amino acids in which one amino acid is limiting

Limiting amino acid
Threonine
Threonine
Threonine
Phenylalanine
Phenylalanine
Phenylalanine
Lysine
Histidine
Cystine tmethionine
Leucine
Valine
Tryptophan

$\begin{array}{cl}\text { Chemical score } & \begin{array}{c}\text { Biological value } \\ \text { (replicates) }\end{array} \\ 50 & 50,53 \\ 60 & 62 \\ 70 & 69,76,64,64 \\ 67 & 68 \\ 38 & 45 \\ 64 & 68 \\ 59 & 52 \\ 58 & 66 \\ 59 & 56 \\ 58 & 61 \\ 70 & 71 \\ 74 & 76,79,80,77,71\end{array}$

The lower end of the correlation was established by preparing a number of mixtures following the pattern of the target mixture but with one amino acid omitted in turn (Table 4). Although the replicates showed greater variation than is usually

Table 4. Biological values for rats of amino acid mixtures completely lacking in one amino acid

\begin{tabular}{|c|c|c|}
\hline \multirow[b]{2}{*}{ Amino acid omitted } & \multicolumn{2}{|c|}{ Biological value } \\
\hline & Replicates & Mean value with its SE \\
\hline $\begin{array}{c}\text { Group I: cystine }+ \text { methionine } \\
\text { valine }\end{array}$ & $\begin{array}{l}17,10,0,0 \\
0,8\end{array}$ & $\begin{array}{l}7 \pm 4 \\
4 \pm 4\end{array}$ \\
\hline $\begin{aligned} \text { Group 2: } & \text { phenylalanine } \\
& \text { leucine + isoleucine } \\
& \text { threonine } \\
& \text { histidine } \\
& \text { tryptophan }\end{aligned}$ & $\begin{array}{l}9,14,20 \\
7,21,23 \\
10,7,17 \\
21,15 \\
26,20,17,27,18\end{array}$ & $\begin{array}{l}15 \pm 3 \cdot 2 \\
17 \pm 5 \cdot 2 \\
11 \pm 2 \cdot 9 \\
18 \pm 3 \cdot 0 \\
22 \pm 2 \cdot 1\end{array}$ \\
\hline Group 3: lysine & $17,33,46,56,51,18,43$ & $38 \pm 6 \cdot 0$ \\
\hline
\end{tabular}

encountered in estimations of $\mathrm{BV}$, the results fell into the following three groups: (I) mixtures lacking valine or cystine plus methionine with a BV of zero, (2) mixtures lacking tryptophan, threonine, histidine, phenylalanine or leucine + isoleucine with a BV of approximately 20 and (3) the mixture lacking lysine (showing an unusually poor replication) with a mean $\mathrm{BV}$ of 38 . 
From the BVs of mixtures of known chemical score a curve was constructed relating these two measurements. Within the limits of experimental error Bvs agreed numerically with the corresponding chemical score at values greater than 50 . Below this value the curve depends upon the limiting amino acid. Only when valine or the sulphur amino acids are limiting does the curve follow the theoretical relation to zero; for other amino acids at $\mathrm{Bvs}$ below 50 the relation curves to meet the $\mathrm{BV}$ axis at levels above zero, namely at 20 for group (2) amino acids above and at 40 for lysine.

\section{Confirmation of the correlation}

The reliability of forecasting $\mathrm{BV}$ from chemical score was tested by analysing a number of proteins for their amino acid content by the Moore \& Stein resin chromatographic technique and comparing the predicted $\mathrm{BV}$ with the value determined by biological assay. The results are shown in Table 5 and verify the prediction with a high degree of accuracy despite the fact that chemical scores are derived from chemical analysis, i.e. from the content of total rather than available amino acids. Such a good relationship would be expected only if the limiting amino acid is fully available.

Table 5. Comparison of chemical score and biological value of various proteins

\begin{tabular}{lccc}
\multicolumn{1}{c}{ Protein } & $\begin{array}{c}\text { Content of } \\
\text { methionine+cystine }\end{array}$ & $\begin{array}{c}\text { Chemical } \\
\text { score }\end{array}$ & $\begin{array}{c}\text { BV } \\
\text { determined }\end{array}$ \\
UNICEF reference milk & $3 \cdot 4$ & 72 & 80 \\
Nigerian dried fish & $3 \cdot 3$ & 69 & 67 \\
Coconut protein isolate & $2 \cdot 6$ & 56 & 66 \\
Coconut & $2 \cdot 5$ & 54 & 54 \\
Cottonseed flour: a & $3 \cdot 2$ & 68 & 65 \\
b & $2 \cdot 9$ & 62 & 63
\end{tabular}

Further confirmation was obtained by predicting and confirming the complementary effect of two proteins. Yellow pea flour was shown by analysis to be limited by methionine + cystine and had thus a chemical score of 43 ; the measured BV was 43 . Maize meal was shown by analysis to be limited by lysine and have a chemical score of 50 ; the measured BV was 35. A mixture of two parts of maize (at I I \% protein) and one part of pea flour (at $27.7 \%$ protein) was calculated to have a chemical score of 72 , limited by methionine. The measured $\mathrm{BV}$ was 70 .

\section{Biological analysis}

The usefulness of chemical score in forecasting $\mathrm{BV}$ is limited by the possible unavailability of part of one or more of the essential amino acids which would not be revealed by chemical analysis but would lower a biological evaluation. Chemical score is numerically equal to BV (when BV is greater than 40 ) only when the limiting amino acid is fully available. Conversely, BV is a measure of the amount of the limiting amino acid that is available if the assay is carried out under the same conditions as those under which the target values were originally measured. Thus if a BV is measured and found to be 60 , the limiting amino acid must be present in available form at $60 \%$ of its target value. 
In this way the truly available amino acid content of individual proteins may be determined by biological analysis and used to compile the available amino acid content of a mixed diet prepared from such proteins.

Such a biological analysis was carried out on bread protein using chromatographic amino acid analysis as a comparison (Table 6). The $\mathrm{BV}$ of bread was $5^{\circ}$, which

Table 6. Amino acid content of bread protein determined by biological analysis (see p. 194) and by chemical (chromatography) analysis

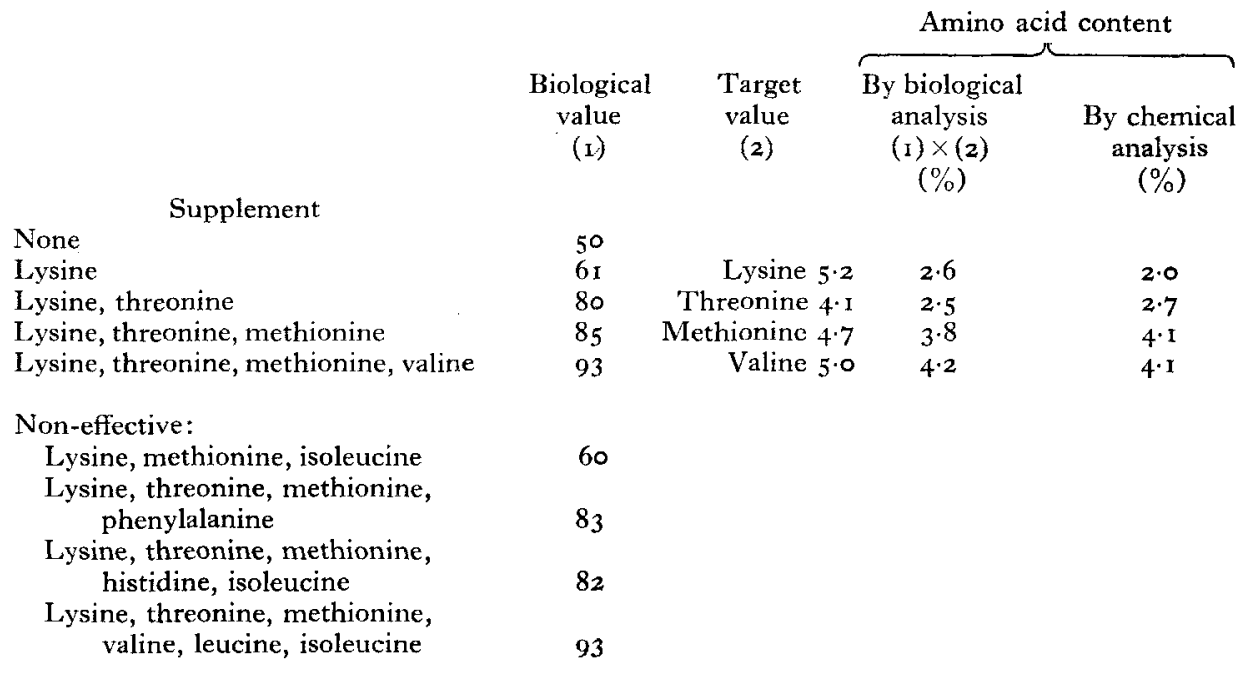

yields the information that the first amino acid was present at $50 \%$ of the target value but does not indicate which amino acid was limiting. The $\mathrm{BV}$ of bread supplemented with lysine was $6 \mathrm{I}$, indicating that the first limiting amino acid was lysine and the second limiting amino acid was present at $61 \%$ of the target value. Thus lysine was not more than $50 \%$ of $5 \cdot 2=\mathbf{2} \cdot 6$, in agreement with chemical analyses, which show a range from $2 \cdot 0$ to $2 \cdot 5$ (Block \& Weiss, 1956 ; McDermott $\&$ Pace, 1960).

Supplementation with lysine and threonine raised the $\mathrm{BV}$ to 80 , indicating that threonine was the second limiting amino acid, present at $61 \%$ of its target value, i.e. $61 \%$ of $4 \cdot 1=2.5 \%$. Chemical analysis shows $2.7 \%$.

Supplementation with lysine, threonine and methionine raised the BV to 85 , showing that methionine was the third limiting acid at $80 \%$ of its target value, i.e. $80 \%$ of 4.7 (value for total sulphur amino acids) $=3.8$ : chemical analysis, $4 \cdot \mathbf{I}$.

Supplementation with lysine, threonine, methionine and valine raised the BV to 93 , indicating that valine was the fourth limiting acid at $85 \%$ of its target value, i.e. $85 \%$ of $5 \cdot 0=4 \cdot 2$; chemical analysis, $4 \cdot \mathrm{I}$.

The finding that chemical scores of incomplete amino acid mixtures agree numerically with $\mathrm{BV}$ and that supplementation raises the $\mathrm{BV}$ according to expectation shows that, apart from leucine and isoleucine, no imbalance occurred at the levels of amino acids used. 
Bender, A. E. (1954). F. Sci. Fd Agric. 5, 305.

Bender, A. E. (1956). Brit. F. Nutr. ro, 135.

Bender, A. E. (1961). In Progress in Meeting Protein Needs of Infants and Preschool Children. Publ, nat. Res. Coun., Wash., no. 843, p. 407.

Bender, A. E. \& Doell, B. H. (1957). Brit. F. Nutr. I 1, I 40.

Berg, C. P. (1959). In Protein and Amino Acid Nutrition, p. 57. [A. A. Albanese, editor.] New York: Academic Press Inc.

Block, R. J. \& Mitchell, H. H. (1946-7). Nutr. Abstr. Rev. 16, 249.

Block, R. J. \& Weiss, K. (1956). Amino Acid Handbook. Springfield, Ill.; C. C. Thomas.

McDermott, E. E. \& Pace, J. (1960). F. Sci. Fd Agric. Ir, Iog.

Miller, D. S. \& Bender, A. E. (1955). Brit. F. Nutr. 9, 382.

Mitchell, H. H. (1959). In Protein and Amino Acid Nutrition, p. I r. [A. A. Albanese, editor.] New York: Academic Press Inc.

Rutgers University: Bureau of Biological Research (1950). Cooperative Determinations of the Amino Acid Content, and of the Nutritive Value of Six Selected Protein Food Sources. New Brunswick, NJ: Rutgers University Press.

\section{The concept of agent and target in amino acid interactions}

\section{By D. Lewis, University of Nottingham School of Agriculture}

It is now generally recognized that the addition to a diet of an amino acid or amino acid mixture beyond the amount required by the animal consuming the diet can on some occasions lead to ill-effects in terms of growth, disproportionate to the amount added. It is possible to attribute all such adverse effects to a single phenomenon, amino acid imbalance (Salmon, 1958), or to attempt to separate them into three categories (Harper, 1958): imbalances, in which the effect of the added amino acid is reversed by supplementing the diet with the first limiting amino acid; antagonisms, in which the effect is reversed by a structurally related amino acid; and toxic effects, in which no simple amino acid supplementation reverses the growth depression. It is not implied that these three categories represent disparate mechanisms, and their continued use seems only to be justified by the apparent absence of any direct evidence to identify a common basis for all the ill-effects that have been recorded (see Harper, 1964). The continuous lack of any substantial evidence to support three distinct mechanisms of interaction makes it necessary still to assume that the situation represents but a single phenomenon.

It can be expected that further information on the nature of the interaction will come from a specific study of the circumstances under which amino acids will bring about and ameliorate a growth-depressing effect. When ill-defined mixtures of amino acids (e.g. proteins or their hydrolysates) are added to a basal diet supporting satisfactory growth it is only possible to acquire further and unnecessary confirmation of the existence of the phenomenon. There is in fact little reason to believe that when mixtures are added the effect is a consequence of more than one of the amino acids present. Each amino acid enters into different pathways of metabolism, and the manner of its involvement in interaction must be understood in terms of its participation in metabolism.

An alternative hypothesis to the division supported by Harper (1958) is to think of the phenomenon as the result of interaction between pairs of amino acids. The 